\title{
A supremacia da escrita sobre a oralidade: uma análise de práticas matemáticas de sujeitos de região de colonização alemã
}

The supremacy of the writing over orality: an analysis of mathematical practices of subjects of a german colonization region

La supremacia de la escrita sobre la oralidad un análisis de prácticas matemáticas de sujetos de región de colonización alemana

\author{
Ketlin Kroetz \\ Pontifícia Universidade Católica do Rio Grande do Sul (Brasil) \\ http://lattes.cnpq.br/0390427253445059 \\ https://orcid.org/0000-0001-8055-8124 \\ ketlin.kroetz@acad.pucrs.br \\ Mônica da Silva Gallon \\ Pontifícia Universidade Católica do Rio Grande do Sul (Brasil) \\ http://lattes.cnpq.br/3410967379937204 \\ http://orcid.org/0000-0003-0793-2372 \\ monica.gallon@gmail.com \\ José Luis Schifino Ferraro \\ Pontifícia Universidade Católica do Rio Grande do Sul (Brasil) \\ http://lattes.cnpq.br/3175334112963316 \\ https://orcid.org/0000-0003-4932-1051 \\ jose.luis@pucrs.br
}

\section{Resumo}

Este artigo problematiza algumas práticas matemáticas escritas e orais de colonos descendentes de alemães de região de colonização alemã do Vale do Rio dos Sinos, e objetiva verificar como as mesmas foram utilizadas por esses sujeitos tanto no período escolar, quanto em suas atividades laborais agrícolas. Os aportes teóricos utilizados para essa investigação estão fundamentados, principalmente, nos estudos de Weber (2002), evidenciando que práticas matemáticas orais se sobressaem nas atividades laborais desses sujeitos, enquanto que no período escolar se observa a legitimação de uma matemática caracterizada pela escrita, evidenciando uma supremacia da escrita sobre a oralidade ao longo da escolarização. Nesse sentido, a utilização de práticas que se valham da oralidade pode converter-se em possibilidade para um constante (re)pensar a educação matemática, uma vez que a escrita prepondera em diferentes instâncias do contexto escolar, produzindo subjetividades que empoderam tal discurso conferindo-lhe o status de único modo possível de matematizar.

Palavras-chave: Oralidade. Escrita. Matemática. 


\begin{abstract}
This article discusses some written and oral mathematical practices of german settlers descendants from the German colonization region of the Vale do Rio dos Sinos, and aims to verify how they were used by these subjects both during the school period and in their agricultural work activities. The theoretical contributions used for this research are mainly based on studies of Weber (2002), that evidences that oral mathematical stand out in these individuals work activities, while in the school period it's observed a legitimization of a mathematics characterized by writing, which confirm a supremacy of the writing over orality throughout schooling. Therefore, the use of orality practices can become a possibility for a frequent (re) thinking of mathematical education, since writing prevails in different instances of the school context, producing subjectivities that empower such discourse, ensuring the status of the only possible mode of mathematize.
\end{abstract}

Keywords: Orality. Writing. Mathematics

\title{
Resumen
}

Este artículo problematiza algunas prácticas escritas y orales de colonos descendientes de alemanes de la región de colonización alemana del Vale do Rio dos Sinos, y objetiva verificar como las mismas fueron utilizadas por esos sujetos tanto en el período escolar, como en sus actividades laborales agrícolas. Los aportes teóricos utilizados para esa investigación están fundamentados, principalmente, en los estudios de Weber (2002), evidenciando que prácticas matemáticas orales sobresalen en las actividades laborales de esos sujetos, mientras que en el período escolar se observa la legitimación de una matemática caracterizada por la escritura, evidenciando una supremacía de la escritura sobre la oralidad a lo largo de la escolarización. En este sentido, la utilización de prácticas que se valen de la oralidad puede convertirse en posibilidad para un constante (re) pensar la educación matemática, una vez que la escritura prepondera en diferentes instancias del contexto escolar, produciendo subjetividades que empoderan dicho discurso que le confiere el status de único modo posible de matematizar.

Palabras clave: Oralidad. Escrita. Matematica. 


\section{Apresentando o estudo}

Os estudos sobre a oralidade e a escrita que se expandiram significativamente no exterior, durante a década de 1970, acabaram por constituir um campo de estudos de natureza interdisciplinar no qual estão circunscritos temas que dizem respeito aos possíveis efeitos cognitivos, socioculturais, linguísticos e políticos da escrita (BATISTA, 2000). A partir disso, as inúmeras pesquisas que vêm sendo realizadas no âmbito da escrita apontam que o seu domínio acarreta alterações no estado de conhecimento de determinada sociedade ou grupo cultural.

Se compreendermos a oralidade como uma prática utilizada por diversos grupos culturais, é fácil evidenciar a existência de tensões entre as práticas orais e escritas, dado que a escrita normalmente é legitimada e configurada como hegemônica na sociedade moderna, enquanto a oralidade, muitas vezes, é marginalizada e vista como inválida (WEBER, 2002). Bunzen (2014, p.14), referindo-se à linguagem escrita, afirma há um desafio imposto de compreendê-la não somente como "[...] um ponto de vista (psico) linguístico, mas também histórico, antropológico e cultural, levando em consideração as relações de poder". A ideia é colocar sob suspeição a legitimidade da escrita, criando condições de possibilidade para as diferentes manifestações da linguagem, entre elas, em sua forma oral.

Em sua tese de doutoramento, Souza (2008), sustenta que a escrita produz verdades e fabrica determinados tipos de sujeito "[...] como pessoas carentes de um modo de raciocínio específico, próprio de quem domina a tecnologia da escrita" (SOUZA, 2008, p. 233). Assim, temos indícios de que escrita tem grande poder na constituição do sujeito moderno, uma vez que é associada tanto ao progresso científico, quanto à cultura acadêmica. Desse modo, desloca-se a oralidade para o "mundo mágico das vozes" (CERTEAU, 1994, p. 224), atribuindo à fala um ar de inferioridade. Diante de tal fato, este artigo problematiza algumas práticas matemáticas escritas e orais de um grupo de colonos descendentes de alemães de uma região de colonização alemã do Vale do Rio dos Sinos ${ }^{1}$, e tem como objetivo verificar como tais experiências foram utilizadas e concebidas por esses sujeitos, tanto no período escolar, quanto em suas atividades laborais realizadas na agricultura.

O material empírico consistiu em enunciados retirados de uma dissertação de mestrado ${ }^{2}$, produzidos por meio de entrevistas semiestruturadas realizadas com três colonos com baixa escolarização ${ }^{3}$. O período escolar dos três sujeitos entrevistados por Kroetz (2015) ocorreu entre as décadas de 1920 e 1930, concomitantemente à época em que as atividades agrícolas representavam o único meio de subsistência das famílias. Ademais, esse período foi

\footnotetext{
${ }^{1}$ A cidade de Santa Maria do Herval pertencia à São Leopoldo na época da chegada dos primeiros imigrantes alemães no Rio Grande do Sul, em 1824. Uma das tradições herdadas pelos imigrantes foi a língua, o Hunsruckish, que embora esteja se perdendo com o passar dos anos, ainda é considerado, principalmente entre os sujeitos mais velhos, como dialeto principal utilizado para a comunicação.

${ }^{2}$ As narrativas foram retiradas da dissertação Etnomatemática e relações de poder: uma análise de narrativas de colonos descendentes de alemães do Vale do Rio dos Sinos (KROETZ, 2015). As entrevistas que produziram as narrativas foram realizadas em Hunsrückisch e transcritas pela pesquisadora para a língua portuguesa após passarem por uma auditoria. O Projeto Hunsrückisch emerge em Santa Maria do Herval em 2003 com o objetivo de preservar e criar um código de escrita para a língua e preservar o idioma das crianças e famílias hervalenses. Coordenado pela professora Dra. Úrsula Wiesemann, da Alemanha, e com o auxílio de colaboradores de Santa Maria do Herval, o projeto foi desenvolvido no Museu Municipal da cidade e em 2008, recebeu o HRX, efetivando o registro como língua no Ethnologue, órgão que cataloga todas as línguas do planeta. Atualmente, o Hunsrückisch é reconhecido parcialmente como a segunda língua oficial da cidade, e é ensinado em algumas escolas do município, desde 2009. O Hunsrückisch é falado na região sudoeste da Alemanha e tornou-se uma língua franca entre os descendentes de alemães das cidades de colonização alemã, expandindo-se com a chegada dos primeiros imigrantes no sul do País e persistindo até o século XXI (KROETZ, 2015).

3 Como a autora adota uma perspectiva etnomatemática, um dos critérios para a escolha dos sujeitos entrevistados foi a baixa escolarização, respaldado na concepção de Ascher e Ascher (1986). Ademais, residir na zona rural, ter trabalhado na agricultura e ser indicado para fazer parte do estudo por informantes, também foram alguns critérios adotados.
} 
caracterizado por um movimento político peculiar, a Campanha de Nacionalização, conjunto de medidas adotadas pelo governo getulista durante o Estado Novo, cujo principal objetivo era diminuir a influência das comunidades de imigrantes estrangeiros no Brasil, forçando sua integração junto à população brasileira (SEYFERTH, 1990).

Visto que as narrativas dos sujeitos são direcionadas a um período do passado, adotouse a história oral como metodologia de pesquisa, visto que por meio dessa é possível concatenar aspectos dos cenários históricos ligados às práticas escolares do passado e compreender os reflexos na atualidade (GARNICA, 2004).

\section{Sobre a História Oral}

A História Oral (HO) é tradicionalmente empregada no campo da História e das Ciências Sociais, e tem como objetivo, conforme Silva e Souza (2007), a valorização das narrativas orais como material de estudo. Nessa perspectiva, passou-se a considerar a utilização da $\mathrm{HO}$ na medida em que os historiadores compreenderam que documentos históricos se mostravam suscetíveis a adulterações (GAERTNER; BARALDI, 2008). No entanto, vale destacar que a utilização dessa abordagem não se trata de admitir a existência de uma história verdadeira. Diante disso, Garnica (2005) ressalta elementos importantes trazidos pela oralidade, tais como dinamicidade, correções de registro e a chance de transformação de objetos de estudo em sujeitos, que por outros instrumentos de coleta de dados talvez não fossem acessíveis. De acordo com Silva e Souza (2007, p. 142):

As narrativas orais são vistas pela história oral como fontes a partir das quais torna-se possível uma maior aproximação dos significados atribuídos às realidades vividas por quem narra, já que busca (em grande parte dos casos) preservar, em uma apresentação quase literal das narrativas coletadas por meio de entrevistas, as legitimidades próprias do narrador.

Os procedimentos requeridos pela $\mathrm{HO}$ abarcam:

A pré-seleção dos depoentes, sondagem dos possíveis documentos que tratam do tema das entrevistas a serem registradas, entrevistas gravadas que constituirão o documento-base da pesquisa, instâncias de transformação do documento oral em escrito: a transcrição literal, a textualização e a transcriação [...]; 'legitimação' [...] e, por fim, um momento de análise, cujo caráter varia segundos os propósitos de cada pesquisa (GARNICA, 2007, THOMPSON, 1998 apud SILVA, SOUZA, 2007, p. 144).

Segundo Gaertner e Baraldi (2008), os relatos obtidos por meio de entrevistas constituem trajetórias individuais e devem ser compreendidos como tal. Também, exige-se do pesquisador, princípios éticos em relação aos entrevistados que devem ser respeitados, já que podem reavivar-se memórias marcadas por emoções e fatos que estavam ocultos. Ainda, outro aspecto importante é que a $\mathrm{HO}$ está condicionada à memória do depoente, e esta é seletiva, podendo criar múltiplas versões de acontecimentos passados (GAERTNER; BARALDI, 2008). Ressalta-se também que, além dos materiais obtidos por meio das entrevistas, o pesquisador pode lançar mão de outras fontes de pesquisa.

Neste estudo utilizam-se fontes orais, baseadas em entrevistas fornecidas por três sujeitos, colonos, moradores da cidade de Santa Maria do Herval, Rio Grande do Sul. Os 
depoimentos aqui analisados são um recorte do trabalho de Kroetz (2015), seguindo-se os procedimentos metodológicos sugeridos para História Oral, buscando contribuições no que diz respeito à compreensão e à negociação dos significados matemáticos para esse grupo cultural (GARNICA, 2005).

\section{Sobre as práticas orais e escritas}

$\mathrm{P}^{4}$ : E como vocês faziam pra controlar tudo o que ganhavam?

EC: O controle era todo comigo, mas eu não precisava anotar nada, sabia tudo na cabeça.

P: Não precisava anotar nada num papel? EC: Nada, eu lembrava das coisas.

EB: A gente fazia as contas mais na cabeça, pra vender, comprar, isso a gente sabia de cabeça, o pai ensinou tudo isso.

P: E como vocês sabiam que valia a mesma coisa [as trocas]? EB: Ahh, isso era no olho, né? Na cabeça. EA: Sim, aí se estou diminuindo e falta um eu peço emprestado, isso aprendemos na escola. Mas eu sempre tinha minhas contas prontas na cabeça antes de ir na venda (mercado)

EA: A gente era muito quieto na escola, um sentado atrás do outro, retinho, quase sem se mexer, só podia olhar pro quadro e copiar.

EB: Os professores escreviam no quadro e deu, tinha que copiar. As crianças estudavam, olha, se a gente pudesse continuar a estudar. Primeiro a gente aprendeu o einmaleins, 1 x 2, sabe? depois o ABC. Primeiro o pai ensinou isso e ele falava: como vocês querem aprender o resto se vocês não sabem isso?

Os excertos acima foram retirados da dissertação de Kroetz (2015). Em seus estudos, onde a autora objetiva identificar e compreender os processos de geração, organização e difusão dos saberes de colonos descendentes de alemães residentes na região do Vale do Rio dos Sinos, verifica que a geração dos saberes desse grupo ocorreu com seus pais e conhecidos, e que os jogos de linguagem ${ }^{5}$ utilizados na agricultura eram diferentes daqueles impostos pela escola. Uma das diferenças apontadas é a de que se na escola predominava a escrita, na vivência dos sujeitos prevalecia a oralidade, por exemplo.

Enquanto nas atividades laborais dos colonos, eles afirmam não precisarem anotar nada, saberem tudo de cabeça, é fácil perceber que a oralidade se constituía uma maneira

\footnotetext{
${ }^{4}$ A letra $\mathrm{P}$ corresponde à pesquisadora; EA, entrevistada A; EB, entrevistado B e, EC, entrevistado C.

${ }^{5}$ Conceito de Wittgenstein (2004). Para o autor, as diferentes regras utilizadas na linguagem compõem um jogo. Essas regras, emergentes em uma forma e vida, fazem com que Wittgenstein (2004) destaque que o real significado das palavras se encontra no uso que se faz delas, num jogo de linguagem estabelecido entre sujeitos. É atribuído, assim, um caráter particular à linguagem, e ela passa a apresentar significado mediante o uso que se faz dela. Ao falar uma linguagem o sujeito está exercendo uma atividade, uma determinada forma de vida, daí a conexão entre a linguagem e a forma de vida, pois esta se encontra imersa numa situação no mundo. Quando o autor se refere à linguagem como parte de uma forma de vida, destaca que a linguagem envolve mais do que simplesmente a fala. Nessa direção, ao mencionar a expressão jogos de linguagem, Wittgenstein (2004) se refere à multiplicidade de usos da linguagem, que são aspectos da forma de vida dos sujeitos. Assim, como a matemática é uma linguagem, existiriam diversas matemáticas, no plural, que fazem sentido conforme o uso que se faz delas.
} 
prática de resolver suas situações cotidianas. No entanto, no período escolar, os mesmos sujeitos destacam que a matemática só era considerada no papel. Ao apontarem a rigidez dos professores, que se utilizavam de mecanismos disciplinares para moldar os estudantes, os colonos afirmam que os conteúdos eram escritos no quadro e que era necessário armar a conta e colocar os algarismos um embaixo do outro nas aulas de Matemática ${ }^{6}$, o que pode ser evidenciado na seguinte passagem: EA: Eram de somar assim [as contas], um embaixo do outro, sabe? Somar e descontar, como eu aprendi na escola. P: As contas eram sempre um embaixo do outro? EA: Sim, aí se estou diminuindo e falta um eu peço emprestado, isso aprendemos na escola.

Percebe-se, então, que a escola era responsável pelo controle e utilização do tempo com técnicas que se ramificavam numa hierarquia de saberes, organizando estágios por meio de provas graduadas, que com fundamento nos escritos de Foucault (1987, p. 135), “[...] comportam exercícios de dificuldade crescente; qualificando os indivíduos de acordo com a maneira como percorrem essas séries". Um dos procedimentos dessa técnica é o exercício, compreendido por Foucault (1987) como uma técnica que impõe diversas atividades repetitivas e intensificadas que obedecem a uma hierarquia, era marcado pela escrita.

Um dos materiais utilizados pelos colonos para realização dos exercícios escolares antigamente era o tafel $^{7}$ e o griffel $^{8}$. Segundo os colonos entrevistados, as tarefas eram reproduzidas em lousas constituídas de pedras lisas de ardósia. Escreviam em sua superfície com um objeto pontudo feito de pedra, chamado por eles de griffel. Como apagador utilizavam um pedaço de pano, mas na maioria das vezes, esfregavam com as próprias mãos. Para Souza (2007, p. 83), a lousa e o quadro-negro "[...] serviam de instrumentos para a criança escolarizada aprender os primeiros movimentos de uma escrita correta.”. Destacam os sujeitos: "A gente usava um tafel, um quadrinho, e escrevíamos com um prego" e "A gente tinha tafel e um griffel. Se caísse no chão quebrava. Mergulhávamos uma peninha numa tinta, só podia mergulhar um pouco, se colocasse muito borrava ainda.". O tafel consistia numa superfície de pedra ou de madeira utilizada como um suporte para a escrita, se mostrando eficiente para auxiliar o professor em sua docência e fazer com que os alunos copiassem o que era necessário

Conforme as narrativas dos sujeitos entrevistados, os exercícios eram copiados do quadro utilizando um tafel e de um griffel (figura 1), dois artefatos com uma simbologia significativa no que diz respeito ao período escolar desses sujeitos

\footnotetext{
${ }^{6}$ A Matemática, escrita com letra maiúscula, diz respeito, nesse estudo, aos conhecimentos transmitidos aos sujeitos na escola, podendo ser chamada de Matemática escolar. Bernstein (1996), ao analisar o discurso pedagógico da física ensinada na escola, aponta que esta se trata do "[...] resultado de princípios recontextualizadores que efetuaram uma seleção e deslocaram do contexto primário da produção do 'discurso' aquilo que conta como Física e o recolocaram, o refocalizaram, no contexto secundário da reprodução do discurso" (BERNSTEIN, 1996, p. 260-261). Tal como a Física, a Matemática escolar é uma recontextualização da Matemática acadêmica e sua legitimidade.

7 Tradução: Painel. Lousa, no singular, ou "quadro de ardósia" - utilizado para traduzir do alemão o substantivo tafel, também chamado de "pedra" e "prancha de traçar", na língua portuguesa; vocábulos citados em Grande Enciclopédia Brasileira (19[-?], p. 160).

${ }^{8}$ O vocábulo "ponteiro" foi utilizado no dicionário ao ser introduzida a palavra "lousa" com a explicação de que nela se escreve ou desenha com "ponteiros da mesma pedra" (FERREIRA, 1999, p. 1049). Para o alemão, seu correspondente seria Griffel.
} 


\section{Figura 1: Tafel e Griffel}
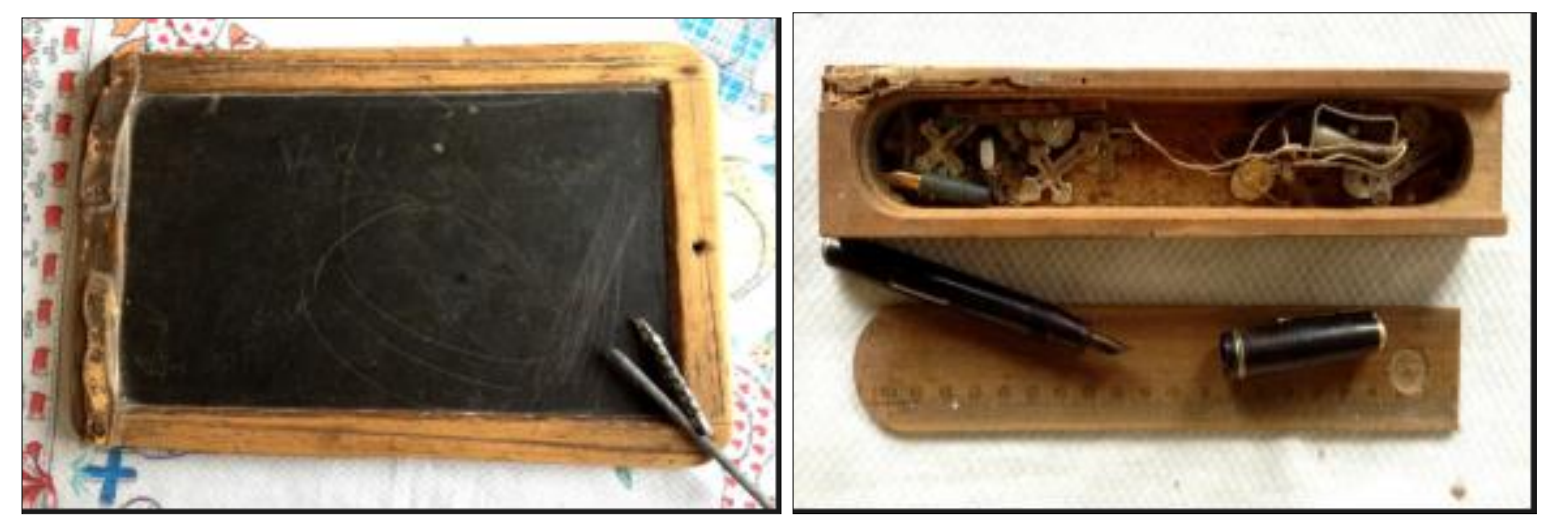

Fonte: Extraído de Kroetz (2015).

Pode-se considerar o griffel como um artefato utilizado para gravar, no taffel, o que o professor escrevia no quadro, tal como evidenciado pela entrevistada A: "A gente era muito quieto na escola, um sentado atrás do outro, retinho, quase sem se mexer, só podia olhar pro quadro e copiar". Percebe-se, então, a existência de uma superioridade atribuída à linguagem escrita no período escolar desses sujeitos, diferente das práticas realizadas na agricultura, onde prevalecia a oralidade. Essa valorização da escrita sobre a oralidade, se tomarmos os escritos de Foucault (1987, p. 157) em Vigiar e Punir, situa os sujeitos em uma espécie de "[...] rede de anotações escritas [que envolvem] documentos que os captam e os fixam". Para Souza (2008), é essa prática escrita que fortalece e hierarquiza a repetição e o treino dos exercícios, como também a utilização de diferentes formas de disposição desses no papel. Tais práticas seriam consideradas como essenciais para que os sujeitos pudessem desenvolver seu pensamento matemático.

Ainda, tem-se a impressão de que os professores, no período escolar desses sujeitos, generalizavam o modo de pensar enfatizando uma hierarquia - naturalizada pelo ensino moderno - às formas de ensinar, o que fica perceptível quando os colonos falam que "Primeiro a gente aprendeu o einmaleins", $1 \times 2$, sabe? Depois, o ABC. Primeiro o pai ensinou isso e ele falava: como vocês querem aprender o resto se vocês não sabem isso? Vamos dizer, $8 \times 4$ quanto isso dá, 32, aí a gente escrevia no tafel inteiro. Se tu não soubesse isso, como continuar?" (Entrevistado B).

Os discursos dos entrevistados confirmam certa racionalidade no que refere à aprendizagem da Matemática. Fernanda Wanderer (2007), ao analisar os discursos sobre a escola e a Matemática escolar de um grupo de colonos descendentes de alemães que frequentavam uma escola rural no município de Estrela, no período da Campanha de Nacionalização, destaca, em se tratando dessa matéria, era "[...] constituída por regras que dizem da importância de decorar a tabuada" (WANDERER, 2007, p. 173). A tabuada e as contas armadas caracterizavam o ensino da Matemática no período escolar dos sujeitos, de uma matemática que não possuía significado algum na cena social em que os sujeitos estavam inseridos, a agricultura.

Emmanuel Lizcano (2004) vai propor uma mudança no modo como nos referimos à Matemática, apontando que temos o costume de "[...] dá-la por su-posta (isto é, posta debaixo de nós, como solo fixo) e desde aí, olhar para as práticas populares, em particular, para os modos populares de contar, medir calcular [...]" (LIZCANO, 2004, p. 125). A partir dessa Matemática escolar - essa recontextualização da Matemática acadêmica -, costumamos

\footnotetext{
${ }^{9}$ Tradução de tabuada.
} 
analisar práticas locais tomando sempre como referência uma Matemática mais avançada. A partir disso, Lizcano (2004, p. 125) aponta que as práticas matemáticas dos outros são deslegitimadas por se parecerem menos com a Matemática que aprendemos na escola: "Mas o que ocorre se invertermos o olhar? Que enxergamos se, em lugar de olhar as práticas populares a partir "da matemática", olhamos a matemática a partir das práticas populares?"

Diferente da matemática ensinada na escola, onde era necessário apresentar o cálculo na forma escrita, a matemática oral praticada pelos colonos entrevistados era permeada por jogos de linguagem marcados pela estimativa, pensamento proporcional e oralidade. Isto pode ser evidenciado a seguir:

EC: Isso mesmo. Depois quando eu fiquei mais velho a gente ganhou adubo pelo Banco do Brasil, e nos davam $40 \%$ de desconto. P: E isso é um desconto bom? EC: Ahh, é sim. É quase metade de desconto. P: E como você faria para saber? EC: Olha só, de 100 são 40, né? Por isso é por cento eu acho. P: Poderia me dar um exemplo? EC: Vamos supor, tu comprou pra $R \$ 1000,00$, tu vai ganhar $R \$ 400,00$. Isso é um desconto bom, imagina... quase metade do valor. EA: Mais ou menos, pra cada $20 \mathrm{~kg}$ de banha mais ou menos a gente utilizava uns $4 \mathrm{~kg}$ de soda. P: E se eu tivesse só $2,5 \mathrm{~kg}$ de soda, quanta banha eu precisaria ter? EA: Uns $12 \mathrm{~kg}$ e 500 gramas. P: Como você sabe disso? EA: Se preciso de $4 \mathrm{~kg}$ de soda pra $20 \mathrm{~kg}$ de banha, então pra $1 \mathrm{~kg}$ de soda preciso de $5 \mathrm{~kg}$ de banha, certo? P: Sim. EA: Então se pra $1 \mathrm{~kg}$ de soda preciso de $5 \mathrm{~kg}$ de banha, pra $2 \mathrm{~kg}$ de soda preciso de $10 \mathrm{~kg}$ de banha. $\mathrm{E}$ o resto eu faço depois. P: Que resto? EA: Os números quebrados. Se pra $1 \mathrm{~kg}$ de soda preciso de $5 \mathrm{~kg}$ de banha, pra meio quilo preciso de $2,5 \mathrm{~kg}$ de banha, né? Então juntando com o 10 dá 12,5kg.

No entanto, ainda que esses colonos utilizassem práticas matemáticas orais para tratar dos negócios e das múltiplas atividades que os acompanhavam em tempos passados, a escrita utilizada na escola funcionava como um mecanismo exercido sempre por aqueles que a dominavam: os professores. Isso também é perceptível quando os colonos afirmam que hoje em dia, pro negócio valer, tem que estar no papel, e que só antigamente podiam fazer negócio combinando no boca-a-boca.

As narrativas elucidam certo tensionamento entre as práticas matemáticas orais e escritas desses sujeitos, na medida em que no período escolar dos colonos, as práticas adotadas eram voltadas à escrita e, na agricultura, os colonos valiam-se de técnicas pautadas na oralidade. Quando os sujeitos optam pela oralidade para eventuais negócios e atividades de cunho agrícola, não possuem necessidade da matemática escrita, e não precisam armar a conta e colocar um embaixo do outro, como fazem na escola. Percebe-se, além dos conhecimentos matemáticos, outros saberes implícitos nas ações desses sujeitos, saberes provavelmente não estimulados na escola, visto que o ensino formal proporcionado a eles estava baseado na aprendizagem da matemática, na alfabetização por meio da língua portuguesa e no ensino da religião.

A escola do século XXI não é muito diferente das escolas frequentadas pelos colonos entrevistados. As práticas orais, nas aulas de matemática, tendem a não ser consideradas, e se o estudante não apresenta um tipo de raciocínio específico ou "adequado" sob o ponto de vista do professor, torna-se frequentemente alvo de intervenções pedagógicas corretivas. A escola, nessa direção, não atende às expectativas dos estudantes, uma vez que para alguns grupos culturais, essa Matemática escolar, advinda da Matemática acadêmica, não faz sentido. Os colonos não precisavam do papel e da caneta para resolverem diversas situações que 
ocorriam em suas formas de vida, e nessa direção vale destacar que as práticas matemáticas orais se distinguem das escritas não só por dispensarem o registro da escrita, "[...] mas também porque são parametrizados por outros valores e intenções (como o pragmatismo na opção pela produção ágil de uma resposta aproximada em detrimento da busca meticulosa da precisão) " (SOUZA, 2008, p. 251).

As tensões entre a oralidade e a escrita, fundamentadas em uma abordagem etnomatemática, são alvo dos estudos de Gelsa Knijnik (2007). A autora destaca que, na escola, as práticas matemáticas escritas possuem mais valor que as práticas orais, estudo realizado pela autora em um assentamento do Movimento Sem Terra, MST, no Rio Grande do Sul. Em seus estudos, Knijnik (2007, p. 36) denuncia o "[...] desaparecimento da matemática oral como prática cultural nos processos educativos.”. Nessa mesma direção, Souza (2008, p. 234) aponta que as verdades construídas sobre a matemática escrita produzem determinados tipos de sujeitos, "[...] aqueles/as que dominam a tecnologia da escrita e por isso são autorizados a 'praticar' a matemática escolar e aqueles/as que ainda precisam dominar essa tecnologia para serem inseridos/as nas práticas matemáticas escolares.".

Assim o domínio da escrita aparece como um dispositivo de poder, pois determina o acesso a um tipo de saber. Em Microfísica do Poder (2014), Foucault descreve os dispositivos como operadores materiais do poder, como um conjunto heterogêneo que engloba enunciados, leis, instituições e discursos, onde o dispositivo é a rede que se forma entre estes elementos (FOUCAULT, 2014). Entre tais elementos, existe um conjunto de jogos que permite a formação de um novo campo de racionalidade, isto é, é a partir deles que as assimetrias das relações se tornam visíveis. Com isso, também se evidencia a relação entre saber e verdade, pois dominar a escrita implica em um poder que repercute na manutenção de um regime de verdade - no caso, o domínio da escrita para que se aprenda uma Matemática oficial, verdadeira. Por sua vez, essa matemática reforçaria os efeitos desse poder fazendo-nos acreditar que sem saber escrever não seria possível saber.

Nesse cenário, podem ser referenciados os estudos da antropóloga francesa Florence Weber (2002) sobre a diversidade do raciocínio dos nativos e as práticas econômicas de famílias no seu país, onde a autora afirma que tais raciocínios nem sempre são explícitos, pois os nativos dispõem de uma pluralidade de sistemas de referência, regras e objetivos, utilizando distintas racionalidades que só fazem sentido no que a autora vai denominar cena social. Weber (2002) destaca que é essa pluralidade de sistemas de medida e cálculo adaptadas à diferentes usos que leva a conclusão, após articular vários estudos realizados em diferentes cenas sociais, de que as unidades de medida adotadas dependem do contexto da prática, e que é a interação que dá significação à transação que ocorre sempre em determinado cenário.

A respeito das compras e dos diferentes negócios estabelecidos na agricultura, os colonos afirmam que nos dias atuais, se não está no papel nada mais vale, e que antigamente os negócios eram feitos por palavra, ou seja, nada era assinado, somente combinado. Estamos tão habituados ao sistema jurídico e institucional de transações que acabamos esquecendo de todas as outras maneiras de realizar um negócio. Weber (2002, p, 162-163) aponta que tal fato é estranho aos nossos olhos, pois "[...] longe das garantias jurídicas oferecidas pelos contratos e pelo direito comercial, que se fazem acompanhar de provas escritas e de assinaturas, elas nos levam ao universo em que a palavra dada e o pertencimento ao grupo são suficientes.". A garantia e a confiança que os colonos depositam um no outro faz com que a oralidade seja marcada, também, por valores que eles consideram essenciais em sua comunidade, como a credibilidade e a confiança estabelecida entre os membros do seu grupo.

Assim, o grupo de colonos entrevistados, ao ser constituído como pertencente a um determinado cenário social onde predomina a agricultura, o trabalho manual, os câmbios de produtos e a troca de trabalho com os vizinhos, são empregados sistemas de medida e cálculo oral que estão diretamente implicados em sua utilização. Um exemplo claro disto é a unidade 
de medida chamada pelos colonos de quarta $^{10}$, unidade essa ensinada pelos seus pais, vizinhos e pessoas da comunidade. Ao serem questionados sobre o que vinha a ser uma quarta, os colonos afirmam:

EA: Uma quarta é mais ou menos 7,5kg. Oito quartas é uma saca. A gente media com quartas, antigamente se falava pouco em quilos. P: Como era então? EA: É que a gente não usava balança, né? Por isso a gente usava quartas e fazia essas trocas. Um pedaço de carne a gente balançava assim na mão e dizia quanto era mais ou menos.

EB: Duas quartas dá um galão inteiro, meio galão cheio de sementes equivale a um quart. Quatro galões cheios dá uns $60 \mathrm{~kg}$, depende do que dá um saco de batata cheio. P: E com milhos, e outras sementes, dá a mesma coisa? EB: Sim, a mesma coisa

P: Então essa era a medida de vocês?

EC: Sim, e se a gente fazia certo, nem precisava pesar que dava isso. A balança [...] só mais tarde chegou. P: E essa medida dava certo pra tudo? EC: Sim, mas tinha que colocar certinho também, né? Eram galões de querosene porque a gente não tinha energia elétrica, né? Daí a gente guardava esses galões pra colocar feijão, batata, e medir. Todos faziam assim antigamente, aí a gente também fazia. Quatro galões inteiros dava um saco cheio.

Esse sistema métrico apresentado pelos colonos utiliza práticas específicas para a pesagem e quantidade dos grãos que serão plantados. Sobre os diferentes raciocínios dos nativos, Weber (2002, p. 160) destaca que

[...] no universo em que o relógio, a balança e o cadastro são onipresentes, seu uso não se impõe uniformemente em todos os domínios da prática nem [...] em todos os universos de relações sociais, em todas as 'cenas sociais'. Além disso, o recurso às técnicas de medida se faz acompanhar, por vezes, de conflitos em torno da legitimidade da medida ou da pertinência das ferramentas. Esquecê-lo, é ceder a uma visão angélica das relações sociais e das relações entre ciência e sociedade.

A unidade de medida adotada pelos colonos, além de fazer parte de uma cena social que só faz sentido no modo de vida dos colonos, é caracterizada por regras do mundo da agricultura, e não possui significado em outras cenas sociais. Weber (2002, p. 160) vai provocar, pontuando: “de que vale uma medida 'científica' para explicar comportamentos se ela não é utilizada, ou seja, percebida, pelas pessoas concernidas?" Na vida dos sujeitos, nas transações comerciais, na agricultura e em todas as estratégias adotadas, as necessidades de matematizar eram outras, e iam muito além do que a escola insistia em lhes cobrar, muitas vezes, de modo rígido e valendo-se de técnicas disciplinares como a vigilância e a punição (FOUCAULT, 1987). Além disso, as práticas orais superam a funcionalidade de registros escritos, onde certamente não fazia sentido recorrer à ciência, ao cálculo exato e formal, uma vez que ele não se apresentava produtivo em suas vivências.

\footnotetext{
${ }^{10}$ Tratava-se de um galão de querosene que, depois de utilizado, servia como unidade de medida para que os colonos tivessem uma base da quantidade de grãos de milho, feijão ou até de batata que caberiam numa saca ou quantas quartas seriam plantadas.
} 
Além da oralidade e da escrita, Weber (2002, p. 168) apresenta o conceito de cálculo econômico, concebendo-o como um modo de vida, uma vez que "[...] as racionalidades práticas não se oferecem sempre à observação sob a forma de raciocínios explícitos, listas de anotações ou atividades medidas, mas podem permanecer automáticas ou inconscientes". Muitos desses modos de matematizar são inconscientes, são feitos por regras e operam por meio de comportamentos e estratégias. Alguns raciocínios são até automáticos e, diante disso, não faz sentido recorrer ao cálculo numérico se existe um modo eficaz de cálculo econômico para minimizarem os gastos e preverem seus orçamentos, por exemplo.

Ao mostrar diferentes formas de matematizar, como organizações, técnicas e previsões dos nativos, Weber (2002) destaca a necessidade de esquecer do cálculo apenas como algo formal, em sua concepção abstrata, pois existem categorias próprias de classificação e incorporação que fazem sentido em algumas cenas sociais. Os escritos de Weber (2002) contribuem com as problematizações que têm sido realizadas em relação à supremacia da escrita, auxiliando a compreender que existem outras maneiras de matematizar e que essas dependem de um contexto, de uma cena social que somente faz sentido para os que estão nela inseridos. Alguns grupos culturais, por exemplo, não utilizam nem a escrita, nem a contagem ou cálculo numérico, mas utilizam técnicas de ordenamento e classificação de categorias que permitem a inferência de determinados gastos. No entanto, tais técnicas e práticas não são legitimadas por não se utilizarem das regras da Matemática acadêmica e, muitas vezes, nem são vistas como matemática.

Uma das formas ordinárias de cálculo encontradas por Weber (2002) em um estudo com horticultores na França é a oralidade, utilizada para passar os orçamentos cujos cálculos eram realizados na cabeça. Tais estratégias de cálculo oral, para Knijnik (2004, p. 233), são "[...] interditadas na escola em nome dos algoritmos escritos". A oralidade representa uma operação cognitiva adaptada às necessidades práticas desse sujeito, onde as técnicas de medição e cálculo não devem nada ao sistema formal (WEBER, 2002). Abandona-se, assim, a concepção abstrata do cálculo e verificam-se as categorias nativas de classificação e incorporação. Souza (2008, p. 235) aponta, ainda, que no ambiente escolar “[...] o uso da escrita funciona, ainda, como um mecanismo de legitimação das práticas matemáticas escolares, ao se impor nesse espaço, muitas vezes, como o único modo, e sempre como o modo mais correto, de se fazer matemática".

A pouca valorização do cálculo mental e a oralidade ainda é motivo de estudo, como evidenciado por Boni, Savioli e Passos (2015), ao demonstrarem que uma das questões que conduzem a isso são as próprias deficiências do professor em sua formação inicial, ressaltando a importância do cálculo mental por se tratar de uma forma mais funcional a ser utilizada no cotidiano. No entanto, assim como verificado no período escolar dos colonos, se torna mais complexa uma avaliação oficial ou uma constatação pelo professor da proficiência do estudante por meio da oralidade (BONI, SAVIOLI, PASSOS, 2015). Isso acaba por produzir tensões entre essas duas práticas matemáticas, “[...] uma matemática que se produz nas urgências da vida, na qual a oralidade é acionada com maior frequência, eficiência e legitimidade, e uma outra, escrita, que atende a demandas em que se valorizam a generalidade, a formalidade e o controle" (SOUZA, 2008, p. 235-236). Tais situações podem ser evidenciadas quando os colonos destacam que para fazer banha, para cuidar dos negócios das vendas das batatas e para a plantação, por exemplo, precisam matematizar de outro modo, pois tais situações vão além dos ensinamentos vistos na sala de aula, que normalmente se encontram pautados em uma matemática escrita que, por vezes, se encontra descontextualizada de situações reais. 


\section{Considerações Finais}

Este estudo, ao apresentar algumas práticas matemáticas escritas e orais de um grupo de colonos descendentes de alemães de uma região de colonização alemã do Vale do Rio dos Sinos, verificou que as práticas matemáticas orais se sobressaem na agricultura e nas atividades práticas dos colonos entrevistados, enquanto a matemática caracterizada pela escrita é legitimada na escola. Existe, no entanto, uma supremacia da escrita sobre a oralidade, passível de ser facilmente verificada no cotidiano das escolas a partir de prescrições de currículos-programa.

Se analisarmos a educação matemática atual, é fácil notar que as práticas orais não possuem espaço no ambiente escolar. Knijnik (2007, p. 37) denuncia o desaparecimento das práticas orais na escola, pois esse desaparecimento produz "[...] efeitos sociais que vão além do fracasso escolar". Diante disso, ainda complementa que

[...] a matemática oral, especificamente aquela vinculada aos processos envolvendo operações de adição, subtração, multiplicação e divisão, assume um papel de maior destaque, exatamente porque tais práticas orais integram, ainda hoje, o repertório de conhecimentos que um número significativo de jovens e adultos possuem (KNIJNIK, 2007, p.37).

As tensões entre o oral e o escrito produzem um discurso de que o escrito tem maior valor do que o que é dito. Tal discurso, conforme Souza (2008), é posto em circulação por muitos sujeitos que habitam o campo da educação, como estudantes, pais, professores, políticas públicas, gestores e comunidade em geral. A utilização constante da escrita na forma de vida escolar dos colonos entrevistados faz com que essa seja vista como a única maneira de ensinar, e o modelo oral de pensamento é empregado pelos sujeitos na agricultura na medida em que utilizam, para cada ocasião, estratégias que divergem das regras impostas pela escola.

Diferentemente do período escolar, onde a matemática mostrava-se como uma disciplina formal e rigorosa, marcada apenas por práticas escritas e contas armadas, ao utilizarem determinados saberes em seus contextos valendo-se da oralidade, a matemática pode ser visualizada de outro modo, não como uma ciência dura, mas como algo que transcende os cálculos exatos e pode ser encontrada nos modos de saber e fazer em diferentes culturas, permeando distintos conhecimentos empregados para determinados fins, não estabelecendo limites disciplinares, mas preocupando-se em solucionar problemas cotidianos do grupo de colonos.

Utilizar práticas que se valham da oralidade pode constituir-se como um dos rumos da educação matemática, uma vez que as práticas escritas ainda se encontram fortemente consolidadas em contextos escolares, produzindo subjetividades que legitimam tal modo de matematizar (SOUZA, 2008).

\section{Referências}

ASCHER, M.; ASCHER, R. Ethnomathematics. History of Science, n. 24, june. 1986, p. 125-144. https://doi.org/10.1177/007327538602400202

BATISTA, A. A. G. Letramentos escolares, letramentos no Brasil. Educação em Revista, Belo Horizonte, v. 1, n. 31, p.171-190, jun./2000. 
BERNSTEIN, B. A estruturação do discurso pedagógico: classe, códigos e controle. Petrópolis: Vozes, 1996.

BONI, K. T.; SAVIOLI, A. M. P D.; PASSOS, M. M. Compreensões e dificuldades de professoras a respeito do cálculo mental. Acta Scientiae, Canoas, v. 17, n. 3, p. 563-577, set./dez. 2015.

BUNZEN, C. Apresentação. In: STREET, B. Letramentos sociais: abordagens críticas do letramento no desenvolvimento, na etnografia e na educação. São Paulo: Parábola Editorial, 2014. p. 7-11.

CERTEAU, M. A invenção do cotidiano 1: artes de fazer. Petrópolis: Vozes, 1994.

FERREIRA, A. B. de H. Novo Aurélio Século XXI: o dicionário da língua portuguesa. 3. ed. Rio de Janeiro: Nova Fronteira, 1999.

FOUCAULT, M. Vigiar e punir: nascimento da prisão. 5. ed. Rio de Janeiro: Vozes, 1987.

FOUCAULT, M. Microfísica do poder. 26. ed. São Paulo: Graal, 2014.

GAERTNER, R.; BARALDI, I. M. Um Ensaio Sobre História Oral e Educação Matemática: pontuando princípios e procedimentos. Bolema, Rio Claro, v. 21, n. 30, p. 47-61, 2008.

GARNICA, A. V. M. História oral e educação matemática. In: BORBA, M. C.; ARAÚJO, J. L. (Org.) Pesquisa qualitativa em educação matemática. Belo Horizonte: Autêntica, 2004. p. XX.

GARNICA, A. V. M. A História Oral como recurso para a pesquisa em Educação Matemática: um estudo do caso brasileiro. In: Comunicação apresentada no V Congresso Ibero Americano de Educação Matemática, Porto, 2005. Disponível em: www.jurandirsantos.com.br. Acesso em: 14 maio 2017.

KNIJNIK, G. Mathematics education and the Brazilian Landless Movement: three diferente mathematics in the context of the struggle for social justice. Philosophy of Mathematics Education Journal, v. 21, p. 1-18, 2007.

KNIJNIK, G. Itinerários da Etnomatemática: questões e desafios sobre o cultural, o social e o político na educação matemática. In: KNIJNIK, G.; WANDERER, F., OLIVEIRA, J. C. Etnomatemática, currículo e formação de professores. Santa Cruz do Sul: EDUNISC, 2004, p. 19-37

KROETZ, K. Etnomatemática e relações de poder: uma análise das narrativas de colonos descendentes de alemães da região do Vale do Rio dos Sinos. 2015. Dissertação (Mestrado em Educação em Ciências e Matemática) - Programa de Pós-Graduação em Educação em Ciências e Matemática, Pontifícia Universidade Católica do Rio Grande do Sul, Porto Alegre, 2015.

LIZCANO, E. As matemáticas da tribo européia: um estudo de caso. In: KNIJNIK, G.; WANDERER, F.; OLIVEIRA, C. J. de (Org.). Etnomatemática, currículo e formação de professores. Santa Cruz do Sul: EDUNISC, 2004, p. 124-138.

SEYFERTH, G. Imigração e Cultura no Brasil. Brasília: Universidade de Brasília, 1990.

SILVA, H; SOUZA, L. A. A História Oral na Pesquisa em Educação Matemática. Bolema, Rio Claro, v. 20, n. 28, p. 139-162, 2007. 
SOUZA, M. C. R. F. Gênero e Matemática(s): jogos de verdade nas práticas de numeramento de alunas e alunos da educação de pessoas jovens e adultas. 2008. Tese (Doutorado em Educação) - Programa de Pós-Graduação em Educação: conhecimento e inclusão social, Universidade Federal de Minas Gerais, Belo Horizonte, 2008

SOUZA, R. M. S. A cultura material escolar da Deutsche Schule. Revista Brasileira de História da Educação. v. 7, n. 2, p. 69-94, maio/ago. 2007. Disponível em:

http://rbhe.sbhe.org.br/index.php/rbhe/article/download/130/140. Acesso em: 7 dez. 2015.

WANDERER, F. Escola e Matemática Escolar: mecanismos de regulação sobre sujeitos escolares de uma localidade rural de colonização alemã do Rio Grande do Sul. 2007. Tese (Doutorado em Educação) - Programa de Pós-Graduação em Educação, Universidade do Vale do Rio dos Sinos, São Leopoldo, 2007

WEBER, F. Práticas econômicas e formas ordinárias de cálculo. Mana, Rio de Janeiro, v.8, n.2, out/ 2002, p.151-182. https://doi.org/10.1590/S0104-93132002000200006

WITTGENSTEIN, L. Investigações filosóficas. São Paulo: Nova Cultural, 2004. 